\title{
Student Teachers' Attitude towards the Use of Indigenous Languages as Medium of Instruction in the Teaching of Science Subjects In Primary Schools of Zimbabwe
}

\author{
Dr Ester Chivhanga, Chimhenga Sylod. \\ Principal Lecturer, Department of Languages, United College of Education, Bulawayo, Zimbabwe, \\ Senior lecturer/Student Advisor. Centre for Student Management, Zimbabwe Open University.
}

\begin{abstract}
The study sought to explore the attitudes of student teachers towards using indigenous languages as medium of instruction in the teaching of Science Subjects in primary schools of Zimbabwe. The aim was to compare the attitudes of student teachers towards the use of English as a medium of instruction and that of ChiShona as medium of instruction in the teaching and learning of Mathematics to Grade 4 classes and to examine the students' attitudes towards the use of mother tongue instruction in the teaching and learning of Mathematics in Zimbabwe primary schools. A practical teaching experiment was used to investigate the feasibility of using ChiShona as medium of instruction in the teaching and learning of Mathematics to Grade 4 class and investigate the student teachers' attitudes in the teaching situation. In addition a descriptive survey research design which used questionnaires and interviews as data collection methods was employed for its usefulness in exploratory studies. Data gathered was subjected to both quantitative and qualitative analysis resulting in data triangulation for validation.
\end{abstract}

Key terms: Language planning, Language policy, Medium of instruction, language attitudes

\section{Introduction and background to the study}

This research study focuses on the feasibility of using ChiShona as a language of instruction in the teaching of Mathematics in primary schools in Zimbabwe and the attitudes of student teachers towards the use of ChiShona as a medium of instruction in the teaching and learning of Mathematics in Zimbabwean primary schools.

Zimbabwe inherited from its colonial past a language policy that marginalises the use of indigenous African languages in the education system. English continues to be the prestige-laden language enjoying high status while indigenous African languages such as ChiShona enjoy relatively low status. English is the medium of instruction in primary, secondary and tertiary education. Indigenous African languages such as ChiShona, received very little attention in terms of use as media of instruction. The continued use of English as a medium of instruction in teaching Mathematics means that no scientific ideas can be formulated using ChiShona in the present schooling system leading to perpetual scientific bankruptcy (Magwa 2009: iii). This study is therefore an attempt to explore the possibilities of using ChiShona as a language of instruction in the teaching of Mathematics to a Grade 4 class and investigate the attitudes of student teachers towards the use of ChiShona as a medium of instruction in teaching Mathematics as a science subjects.

An examination of the Zimbabwean linguistic situation indicates clearly that there is a linguistic discrepancy. The language of government is not the language of the governed. The language of the majority of people in Zimbabwe does not feature much in the development discourse. Postcolonial Zimbabwe is an example of neglected multilingualism with an unbalanced bilingual behaviour by its citizenry. English has firmly entrenched itself as the language of government, business, the media, education, training and specialized information, as well as upward mobility and wider communication within and outside Zimbabwe's borders (Chimhundu, 1993:57). African languages are predominant in what are perceived to be the relatively unimportant family, social and cultural domains and continue to be downgraded particularly in the educational system and in public life. The government is more comfortable in using the same colonial language policies that were used in the past by the colonial minority to keep the majority of Zimbabwe, disempowered by making grassroots participate in national issues and debate difficult if not impossible (Chimhundu1993). The Government hid behind the unfounded myths that say promoting indigenous language would be equated to promoting tribalism (Magwa 2010). According to Magwa (2010: 8) this mentality created no serious attention to the language issues of Zimbabwe leaving English to dominate the language map of Zimbabwe and even in the teaching of mathematics.

Decades after attaining independence, African countries remain prisoners of the past with constraint reinforced by the argument that English is going to be needed for higher education, technology, science and industry (Bamgbose, 1991:72). The question is what and where is the problem? Indigenous languages have not 
been associated with access to modern education and technology, so non-African languages considered to equip the learner with access to rapid economic development and social mobility are preferred. Secondly speakers of indigenous languages are not economically and technologically empowered to determine their destiny.

The Zimbabwean language policy adopted at independence which is enshrined in the Education Act of 1987 (as amended in 1990, 1996 and 2006) enhances the importance of English as the language of business, administration, teaching and international relations. The Act only allows the teaching of ChiShona and IsiNdebele from Grade 1 to university level as subjects. It states that from the fourth grade, English shall be the medium of instruction. ChiShona is not used at all as media of instruction in other subjects in the primary schools of Zimbabwe. According to Magwa (2009) English language thus remains the official medium of instruction in schools, a compulsory subject and also a requirement on all school certificates. The medium of instruction is viewed to have a strong bearing on how the learner will adjust and work effectively at school (Mavesera 2009). Hence this research seeks to examine the attitudes of student teachers in using ChiShona as a medium of instruction in primary schools.

Batibo (2005:36) maintains that indigenous languages should not be seen as stumbling blocks to national unity, national identity and national development but should be regarded as resources for people's aspirations and full participation in national development. In view of this the language of education should be that which offers potential for full participation by the masses. However the question that remains is: "Are African Indigenous languages, for example, ChiShona, in a position to be effectively and efficiently used as media of instruction in education especially for scientific subjects such as Mathematics?"

ChiShona is spoken by $80 \%$ of the Zimbabwean population (Hachipola 1998, Batibo, 2005:84). It is the mother tongue for most of the learners in primary schools of Zimbabwe. In class English is their language of instruction in the teaching of science subjects such as Mathematics and their mother tongue is marginalised. Although ChiShona is spoken by the majority of the children in primary schools, it has not assumed any significant role as a national indigenous language and its acceptance as a language of instruction to Mathematics by student teachersin tertiary institutions leave a lot to be desired.

The mother tongue is a production tool that facilitates thinking and sharing of ideas in a teaching and learning situation. Studies have shown that instruction in the mother tongue is beneficial to language competence in the first language, achievement in other subject areas and training in a second language (UNESCO 2003). According to Pattanayak (1981: 55) 'instruction in the mother tongue helps in the search for self- affirmation, establishes group identity, satisfies the rational urge for cultural footedness and avoids fanatics in concept formation, critical thinking, creativity and in important social values'. In other words, children who begin their education in mother tongue make a better start, demonstrate increased self- confidence and continue to perform better than those who start school in a foreign language. This is supported by the 1951 UNESCO resolution which asserts that the best medium for teaching a child is the child's mother tongue. The researchers undertook this study in order to examine the attitudes of students in tertiary institutions on the use of ChiShona( mother tongue) as a medium of instruction in the teaching and learning of Mathematics in primary schools.

Researchers such as McNamara in Chiwome (1992:248) established that learning takes longer in a foreign language (English) than in the mother tongue (ChiShona). This means that mother-tongue tuition ensures linguistic accessibility to studied material, helps to develop critical thinking and to foster effective communication. According to Mutasa (2003:306) mother tongue instruction results in improved learning achievements, better adjustments to school, cultural preservation and self-confidence in children. Learners are likely to grasp learning concepts much easier if educational materials are written in local languages and concepts taught through the mother tongue. It is also recommended on psychological, social and educational grounds that children be taught in a language they know effectively, which will normally be the mother tongue of the children.(Webb 2002:192). A language that a child knows effectively should be the language of education and training which is capable of opening communication barriers. According to Webb (2002) where the language of instruction is the same as the mother tongue, it gives confidence to a learner with respect of their cultural heritage and historical baggage. In other words learning through a mother tongue leads to selfrealisation and self-actualisation. With the above discussed characteristics of mother tongue instruction one wonders why Zimbabwe, after thirty four years of independence, is not considering indigenous languages such as ChiShona to be used as media of instruction in the teaching and learning of subjects in primary schools and why students in tertiary education develop negative attitudes towards the use of ChiShona as medium of instruction in Mathematics. ChiShona is equally an important language and there is nothing that cannot be articulated in ChiShona hence if other languages like English are used, why not ChiShona. This study is an attempt to explore the attitudes of tertiary students towards the possibilities of using ChiShona as the official medium of instruction in the education system, the rationale being that indigenous languages are accorded little value in the education system of Zimbabwe. Educational policies in the country on the other hand, have been coined along European lines in order to maintain European hegemony over Africans resulting in the marginalization of indigenous languages in official domains. 
In Zimbabwe, Ngara (1982) acknowledges that University of Rhodesia students in the1960s used to regard English Honours degree as prestigious whereas a degree in ChiShona had a low reputation and the Africans had a negative attitude towards their own language. This is the root cause of the current negative attitudes towards the use Chishona as a medium of instruction in the teaching of primary school subjects such as Mathematics by learners. Rwambiwa's (1996) findings confirmed that pupils often humiliated teachers of ChiShona and other African languages by expressing negative attitudes towards learning indigenous languages. Rwambiwa (1996) argues that such attitudes, expressed by learners towards the mother tongue, are encouraged by the language policy of 1987 which requires learners to learn all subjects, including Mathematics in English beginning in Grade 4.

Learner attitudes can also be explained in terms of influence from teachers. When teachers undermine the children's L1 and use English as the medium of instruction from the first grade, this may result in children having a negative attitude towards their mother tongue (ChiShona ) being used as a medium of instruction in teaching Mathematics at primary school level. According to Murray and Smith (1988) this attitude comes about possibly because when their mother tongue is not used for educational purposes, children may not attach any importance to it.Ndamba (2008) in her study found that children liked to speak in the mother tongue more than English during lessons. This may be due to the fact that these children, who all indicated that they speak ChiShona/IsiNdebele at home, may find it free and natural to express themselves in their mother tongue during lessons (Ngara 1982).

\section{Statement of the problem}

There is a perpetual denial of our indigenous languages, such as ChiShona, to be given a chance to flourish and help promote our culture and national identity through its use as a language of instruction in teaching Mathematics in schools, hence the need for an urgent redress of this anomaly. As tools of communication, indigenous African languages, for example, ChiShona, have the potential to make a very big contribution in development, education, entertainment, information and also fill in the position of English as an official language of instruction in Zimbabwean schools. The continued use of English as a medium of instruction implies that no scientific ideas can be formulated using ChiShona in the current Zimbabwean education system resulting in scientific bankruptcy. This study is therefore an attempt to explore the attitudes of student teachers towards the possibilities of using ChiShona as a language of instruction in the teaching of science subjects such as Mathematics in schools

\section{Research Methodology}

This study combined both qualitative and quantitative research approaches in an effortto obtain accurate outcomes and sufficient information from the respondents. In order to measure the students' language attitudes towards the use of ChiShona as a medium of instruction in the teaching of mathematics in schools, student teachers' questionnaire based on the students' experiences of learning mathematics using ChiShona as a medium of instruction in schools were administered to the teachers. In addition a practical teaching experiment was used to find out the feasibility of using indigenous languages as medium of instruction in the teaching of Mathematics to a Grade4 class.

\section{Instrumentation}

\section{a) Practical teaching experiment}

The practical teaching experiment was used in this study. In an experimental design "the investigator has some control over what will happen to the subjects by systematically imposing or withholding specified conditions. It is a procedure for investigating cause and effect relationships by randomly assigning subjects to groups in which one or more independent variables are manipulated. The intent of an experiment is to compare the effect of one condition on one group with the effect a different condition has on a second group, or to compare the effect of different conditions on the same group. Typically, the researcher then makes comparisons between subjects who have had and others who have not had the imposed conditions" (Schumacher1993:32). This experimental design involves a pre-test and post-test comparison group approach in the practical teaching phase. In the pre-test and post-tests design groups for learners are given a pre-test then the practical teaching and then the post- test.

Twenty mathematics student teachers( Group A), doing their third and final year in teachers' training at United College of Education in Bulawayo, were asked by the researcher to teach the same topic in Mathematics using ChiShona as a medium of instruction to Grade 4 pupils during their teaching practice session. Another group of twenty studentteachers(Group B), doing their third and final year in teachers' training at United College of Education in Bulawayo, were asked by the researcher to teach the same topic in Mathematics as in Group A using English as a medium of instruction to Grade 4 pupils during their teaching practice session. In this study Grade 4 classes were sampled and used for practical teaching to test the feasibility of using ChiShona 
as a medium of instruction in the teaching of mathematics and also establish the attitudes of student teachers towards the use of ChiShona as a medium of instruction. The Grade 4 classes were used for the study because this is at the transitional level when learners switch from ChiShona to English as required by the Educational Act 1987. Sampling is a way of selecting a given number of persons from a defined population as representative of that population (Borg and Gall, 1996). When sampling, the researcher conveniently drew representatives of Grade 4 classes from a large population of Grade 4 classes in primary schools as this saved time and expenses that would have been incurred if one had to study the whole population. Permission was sought from the Ministry of Education to teach the Grade 4 Classes in Bulawayo and Midlands provinces after hours for the sake of this research. The classeswere of a mixed ability stream. The Grade 4 classeswere rich in information such that the information from the experiment could be easily generalised to the entire population under research.

\section{b) Questionnaires}

Before the questionnaires were used a pilot study was carried out in Bulawayo with 20 people to test whether the instrument is intelligible. The researcher carried out group administration of the questionnaires which had advantages of high response rate, shorter data collection time and gave the researcher a chance to verbally explain the purpose of the survey and answer any questions from the respondents.

A questionnaire is a form prepared and distributed to respondents to secure responses to certain questions (Borg and Gall, 1996:320). Seliger and Shohamy (1989:172) define questionnaires as printed forms of data collection, which includes questions or statements to which the subject is expected to respond. In this study the questionnaire was used to extract data that was embedded deep in student teachers concerning their attitudes, feelings or reactions towards the use of ChiShona as a medium of instruction in the teaching of mathematics in primary schools. The questionnaire was administered to 40 Group A and Group B student teachers from United College of Education.

\section{Research findings}

The success of using ChiShona as a medium of instruction in the teaching of Mathematics in primary schools depends on people's attitudes and will to actually implement it. Language attitudes are best appreciated by closely examining their origin. An attitude is an organized predisposition to think, feel, perceive, and behave toward referent or cognitive object an enduring structure of beliefs that predisposes the individual to behave selectively toward attitude referent (Kosslyn and Rosenberg, 2006: 738). Attitudes are the "very general evaluations that people hold of themselves, other people, objects and issues" (Tesser, 1995: 196). In short, an attitude is a disposition to respond favourably or unfavourably towards an object, person, institution or event. Attitudes locate objects of thought on dimensions of judgment. Such a disposition can be towards language (referent object) that may be viewed favourably or unfavourably. Attitudes take a positive or negative direction with very few cases being neutral (Kosslyn and Rosenberg, 2006). Since attitudes to language form a belief (in individuals) in relation to the referent object, their effect on language policy change cannot be taken for granted since they play an important role leading to either acceptance or perspective of the parents rejection of language policy change. It is imperative that language attitudes of users be taken into account before change in the language of instruction is affected. There are several significant questions that asked of the respondent to provide answers which showed the student teacher's attitudes towards the use of ChiShona as medium of instruction in teaching Mathematics in primary schools. One of the questions from the questionnaire was:

Which language of instruction is mostly likely to give primary school learners a clear understanding of mathematical concepts in a teaching learning situation in Zimbabwe?

The students teachers indicated on the questionnaire that English was the language of power and prestige in Zimbabwe and that English is the official language of instruction in the education system of Zimbabwe. Hence, English dominates other African languages as evidenced by the responses of the parents, learners, teachers and lecturers. One of the reasons that these respondents opted for English was that one becomes globally marketable in industry and commerce. Such a view would not support the use of ChiShona as a language of instruction in teaching Mathematics. Views that English is more important than ChiShona have been passed on to children by parents who tell children that English is prestigious and provides educational and employment opportunities in the future (Nondo, 1996). The student teachers develop negative attitudes towards the indigenous languages which they regard as less important (Bamgbose, 1991). This is supported by one of the student teachers who pointed out that, one of his Grade 4 pupils argued that "Kudzidza Maths neChiShona zvinobatsirei? ChiShona chinodzidzisa ChiShona, kwete mamwe ma subjects. Zvinoti dzikisira. Baba havazvide." (Does it help to learn Mathematics using ChiShona? ChiShona should be used to teach ChiShona, and no other subjects. It lowers our social status. My father does not like it.)

Another significant question on attitudes from the Questionnaires was:

What do you think is the attitude of Zimbabweans towards mother tongue instruction in the teaching of Mathematics in primary schools? 
The respondents to this question believed that most of the Zimbabweans would prefer English as the medium of instruction in education. Most interviewees felt that English offers them better opportunities for employment compared to ChiShona. However, English was seen as empowering them to compete well in the global village. English guarantees them "access to the system and equal opportunity to participate in it" (Adegbija, 1994: 3). As such, changing to indigenous languages such as ChiShona is viewed as a direct threat to their (respondents) perceived job opportunities, thus attracting negative attitudes. The aforementioned observations led to the conclusion that language attitudes of users, whether cognitive, affective or behavioural, matter much in language planning. Unless and until attitudes change favourably towards the proposed language, users will continue to reject the intended language innovation.

In the then Rhodesia (colonized Zimbabwe), the colonialists legislated English language as the only medium of instruction in schools. The chain reaction leading to the subsequent dominance of English in the school curriculum was set off in 1903 following the first education ordinance (Atkinson, 1972). Through a subtle tutelage Africans in Zimbabwe came to regard English, and indeed associate it with knowledge, goodness, sweetness and an array of other positives. Those who could speak it received commendation and were made to feel that they were far better than those who could not speak it. For most Africans, English became synonymous with knowledge and education. Speaking good English was, wrongly of course, seen as an indicator that one was educated. English was thus, associated with good life and as such, attitudes towards it became favourable. Those unable to speak English were regarded as backward. This seems to emanate from the notion that a well "schooled" child is one who is conversant and fluent in the English language. English is therefore, viewed as language for prosperity.

Gudhlanga (2005) attribute the negative attitudes towards the use of African languages as languages of instruction in education, to the fact that the current language policy requires children to learn in the mother tongue only in the lower grades. Children will eventually have to learn in English and will be required to pass English as a subject in order to obtain a full "O' level certificate. The emphasis on passing English at 'O' level adversely affects the students' interest in studying ChiShona as a subject in secondary schools (Chivhanga (2008). This definitely impacts on students' zeal to learn the subject and hence, they fail to perform well in ChiShona 'O' level examinations. As a result student teachers viewed English as a gateway to success and consider ChiShona as a language that is not economically viable. This was demonstrated by one student teacher in this study who, with reference to the use of ChiShona as the language of instruction in Mathematics, says, "Ndinodaro nekuti ndiwo mavambo akashata. Kana vana vazosvika pabvunzo dzavo mufomu 4 zvinozovaremera towana kuti mwana ane mamwe ma'subject' asi chirungu asina." (I say so because that is a bad beginning. When children get to form four examinations it will be difficult for them, resulting in them passing other subjects but not English language).

The practical teaching experiment intended to have first-hand experience of teaching Mathematics using ChiShona, an indigenous language, as a medium of instruction. This provided answers to the feasibility of using ChiShona as a medium of instruction in the teaching of Mathematics to primary school children and establishes how the learners develop the concepts of Mathematics in ChiShona. The intent of an experiment is to compare the effect of one condition on one group with the effect a different condition has on a second group, or to compare the effect of different conditions on the same group. Typically, the research made comparisons between subjects who have had and others who have not had the imposed conditions (Schumacher, 1993:32).

The findings in chapter four indicated that if Mathematics is to be taught in ChiShona it means the teaching material should be readily available in ChiShona. Lack of teaching material for Mathematics written in ChiShona was a barrier in this study. Mathematical jargon and other important terms were borrowed or translated into ChiShona from English. Translation of mathematical terms from English to ChiShona enabled the Grade 4 learners to understand the concepts in their mother tongue. This is supported by Ranaweera cited in Brock-Utne who says:

The transition from English to the national languages as the medium of instruction in science helped to destroy the great barrier that existed between the science-educated elite and the non-science-educated masses, between science itself and people. It gave confidence to the common man that science is within his reach and to the teachers and pupils that knowledge of English need not necessarily be a requisite for learning science. The value of mother-tongue instruction is literally incontestable(Brock-Utne, 2000:153).

The medium of instruction is viewed to have a strong bearing on how the learner adjusts to primary school life as it either provides a smooth handover-takeover from the home to the school system or a rough grab that might result in frustrating the learner.(Prah, 2005:26). The teaching of the concepts of Addition and Subtraction (Kusanganisa neKubvisa) involved the use of teaching aids like sticks and stones, and even playing games such as 'Nhodo' to explain the concepts of counting and addition. The Grade 4 learners in Group A interacted freely through the use of their mother tongue. With regard to this, Nyota and Chikodzi (2010) noted that rural learners use their everyday experience to illustrate mathematical concepts. Even though English is the main medium of instruction, teachers in the rural areas use ChiShona to explain mathematical concepts and 
activities whenever possible and such explanations are more extensive during the introduction of new learning concepts (Nyota and Chikodzi 2010). The continued use of ChiShona as a medium of instruction in lessons of Group A facilitated their understanding as they could easily relate the concepts to their environment.

The student teacher's attitude towards the use of ChiShona as medium of instruction in the teaching of Mathematics affected the Grade 4 learners' performance and participation. The student teachers felt that their parents did not want them to learn Mathematics using ChiShona as this would never help them in future. One of them said "Kudzidza Maths neChiShona zvinobatsirei? ChiShona chinodzidzisa ChiShona, kwete mamwe masubjects. Zvinoti dzikisira. Baba havazvide.” (Does it help to learn Mathematics using ChiShona? ChiShona should be used to teach ChiShona, and other subjects. It lowers our social status. My father does not like it.). The attitudes that English is more important than ChiShona is passed on to children by parents who tell children that English provides educational and employment opportunities in the future (Nondo1990). Thus children develop negative attitudes towards the first language which they might then regard as less important (Bamgbose 1991). All in all, the learners in Group A showed an improvement on their performance after they had been taught using ChiShona, their mother tongue, as medium of instruction in learning Mathematics at Grade 4 level.

The language of instruction or the language in which education is principally conducted, is one of the most far-reaching and significant features of any education system. Adegbija (1994) and Mutasa (2004) emphasize that mother tongue education ensures learners' performance at the maximal ability and psychological support. Children who begin their education in mother tongue make a better start, demonstrate increased self confidence and continue to perform better than those who start school in a foreign language. Mother tongue promotion in school helps develop not only the mother tongue but also children's abilities in school. Where the language of instruction is the mother tongue, it affirms the developmental capacity of the mother tongue to grow as a language of culture, science and technology (Magwa 2008). It further provides confidence in the learners and greater understanding of what they learn. When a mother tongue, such as ChiShona, is used as the language of instruction, it becomes an instrument for the cultural and scientific empowerment of people.

During the lessons some learners from backgrounds where English communication is non-existent had difficulties in communicating in English. This even forced the teacher to use their mother tongue (ChiShona) in giving illustrations, demonstrations and instructions for them to understand the mathematical concepts being taught. This change of media of instruction is even supported byMackey (1984) who argues that mother tongue instruction should be promoted to enhance concept formation and include a majority of the indigenous learners who grapple with English. According to Chivhanga (2008), the ChiShona learners use English from Grade 4 as the medium of instruction and one subject that they perform badly in is Mathematics. Language is one of the variables leading to the high failure rate. One proof to this pathetic learning situation is that Mathematics teachers have been observed to code-switch a lot from English to ChiShona as they attend to their classes (Nyota 2009).

A language (ChiShona) that a child knows effectively should be the language of education and training. The language used for education purposes should be a language capable of opening communication barriers. If a language creates a host of "misunderstoods" then the "barriers" cannot be easily cleared (Magwa 2008). The use of mother tongue as a medium of instruction ensures that learners are taught in a language that they are familiar with, is useful in local and national life, can be related to their environment and experience of their day to day life. Chaudron (1988) asserts that in a learning situation where only the L2 is used as a medium of instruction, students face problems because the students have to make sense of the instructional tasks which are presented in the second language.

\section{Conclusions}

This research indicates strong evidence that parents, teachers/lecturers and college/university learners have a negative attitude towards the use of ChiShona as a medium of instruction in the teaching of Mathematics. Results consistently show that the majority of respondents did not prefer the use of ChiShona as medium of instruction at primary school level. Most of the respondents preferred that English remain the only medium of instruction from primary up to university level and they felt that English offers them better opportunities for employment compared to ChiShona. English was seen as empowering them to compete well in the global village. English seems to guarantee them "access to the system and equal opportunity to participate in it" (Adegbija, 1994: 3). Attitudes to indigenous languages as subjects on the curriculum are still negative in some educational institutions. The languages are seen as soft options or where their teaching is made compulsory, an unavoidable drudgery. Even where an indigenous language is a compulsory subject, it is rarely made compulsory for purposes of certification or admission to the next level of education (Mavesera 2009). Research has also shown that people think that English is more important than ChiShona/ IsiNdebele and this has been passed on to children by parents who tell children that English is prestigious and provides educational and employment opportunities in the future, (Nondo 1996). The children begin to develop negative attitudes towards 
the indigenous languages which they might then regard as less important (Bamgbose, 1991; Robinson, 1996; Adegbija, 1994).

Contrary to the above negative view some of the student teachers interviewed in this study had positive attitudes towards the use of ChiShona as a medium of instruction in education. They believed that the use of mother tongue as a medium of instruction ensures that learners are taught in a language spoken by a large number of people, which is useful in local and national life and the language which is familiar to both learners and teachers. Some participants pointed out that indigenous languages could be used as tools of economic empowerment by conveying economic ideas because not all indigenous people are conversant in English. This is a positive attitude towards the use of indigenous languages as languages of instruction in schools.

\section{References}

[1]. Adegbija, E. 1994. Language attitudes in sub-Saharan Africa: A sociolinguistic overview. Clavedon: Multilingual Matters Ltd.

[2]. Ajzen I (1988). Attitudes, Personality and Behaviour. Milton Keyness: OUP, p. 4.

[3]. Atkinson N (1972). Educational Co-operation in the Commonwealth: An Historical Study.

[4]. Series in Education. Occasional Paper No. 1 (1972). Salisbury: University of Rhodesia, p. 265.

[5]. Bamgbose, A. 1991. Language and the nation: The language question in Sub-Saharan Africa. Edinburgh University Press.

[6]. Batibo, H. M. 2005. Language decline and death in Africa: Causes, consequences and challenges. Clevedon: Cromwell Press Ltd.

[7]. Borg, W. R. and Gall, M. P. 1996. Educational Research: An Introduction. New York McKay Company.

[8]. Brock-Utne, B. 2000. Whose education for all? The recolonisation of the African mind. New York: Falmer Press.

[9]. Chimhundu, H. 1993. 'The status of African Languages in Zimbabwe'. SAPEM, October 1993, 57-59.

[10]. Chivhanga, E. 2008. The diglossic relationship between Shona and English languages in Zimbabwean secondary schools. Unpublished dissertation, Pretoria: Unisa

[11]. Chiwome, E. M. 1996. A social History of the Shona Novel. Effel Flats: Juta Zimbabwe Pvt Ltd.

[12]. Gudhlanga, E. S. 2005. 'Promoting the use and teaching of African Languages in Zimbabwe.' In ZJER 17 No. 1 pp 54-66.

[13]. Kerlinger FN 1986. Foundations of Behavioural Research (3rd ed). New York: Holt, Rinehart and Winston, pp. $453-456$.

[14]. Kosslyn SM, Rosenberg, R. S. 2006. Psychology in Context (3rd eds). New Delhi: Pearson Education Inc, p. 738.

[15]. Makey, W. F. 1984. "Mother Tongue Education: Problems and Prospects". In Prospects Vol 14 No. 1 p 37 - 49.

[16]. Magwa, W 2008 Planning for the Future: Exploring Possibilities of Using Indigenous African Languages as Official Languages of Instruction in Education - The Zimbabwean Experience Unpublished Dlitt Thesis ,UNISA, Pretoria Unisa

[17]. Mavesera, M. 2009 Empowerment through language: exploring possibility of using African languages and literature to promote socio-cultural and economic development in Zimbabwe, Unpublished Thesis, Pretoria: Unisa

[18]. Mutasa, D. E. 2004. People Speak: Language Policy and Language use in South Africa. Simba Guru Publishers.

[19]. Mutasa, D. E. 2003. The Language policy of S. A.: What do people say? Pretoria : Unisa.

[20]. Murry, J. and Smith, F. 1988. Language Arts and the Learner. Melbourne, Mcmillan.

[21]. Ndamba. G. T. 2008. An Examination of Language Preferences in Zimbabwe, The Journal of Pan African Studies, vol.2, no.4, June 2008

[22]. Ngara, E. A. 1982. Bilingualism Language Contact and Planning, Proposals for Language use and Language Teaching in Zimbabwe. Gweru: Mambo

[23]. Nondo, S. J. 1996. The main problems faced by students whose mother tongue are other Zimbabwean African languages in learning Ndebele. University of Zimbabwe, Unpublished.

[24]. Nyota, S 1999 Dudziramutauro reChishona 'O' level, Harare, Academic Books

[25]. Nyota S. And Chikodzi I. 2010 The interplay of culture and mathematics: the rural Shona classroom, The Journal of Pan African Studies. Vol 3 Number 10, September 2010

[26]. Pattanayak, D. P. 1981. African language Planning Policies at the University of Venda. Unpublished MA dissertation, University of Cape Town.

[27]. Prah, K. K. 2005. Language of instruction for education development and African emancipation. In B. Brock - Utne and R. K. Hopson (Eds). Languages of instruction for African emancipation: Focus on post-colonial contexts and considerations. Cape Town: The Centre for Advanced Studies of African Society (pp 23 - 50).

[28]. Rwambiwa, J.P. 1996. "Indigenous Languages: An Answer Towards Economic Independence - A Simpler Case for Zimbabwe." Harare, p. 1

[29]. Rwambiwa, J.P. 1993. "The struggle for liberation continues: The need for a revised and positive approach to African languages" in Tonota Journal of Education, Vol 3 no 1 36-40 Tonota Botswana

[30]. Seliger, H.W. and Shohamy, E. 1989. Second language research methods. Oxford: Oxford University Press.132

[31]. Schumacher, S. 1999. Research in education: a conceptual introduction, NewYork : College Press.

[32]. Tesser A 1995. Advanced Social Psychology. New York: McGraw-Hill Inc, pp. 196- 222.

[33]. UNESCO. 2003. Education in a Multilingual World. Paris: UNESCO

[34]. Webb, V.N (ed). 1995. Language in South Africa, an input in language planning for a post-apartheid South Africa. Pretoria: University of Pretoria 